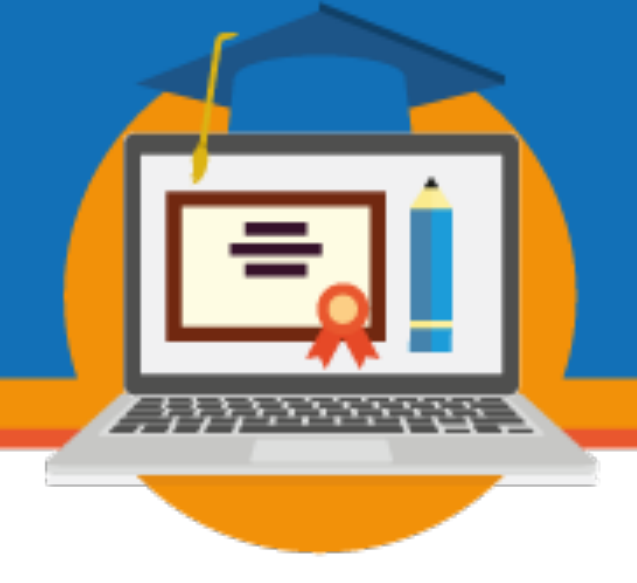

\title{
A CONTRIBUIÇÃO DOS CURSOS EAD NA EXPANSÃO DA OFERTA DE GRADUAÇÃO DA UFGD - 2013 A 2018
}

\author{
Regina Farias de Souza' \\ Universidade Federal da Grande Dourados \\ fsreginafarias@gmail.com \\ Giselle Cristina Martins Real ${ }^{2}$ \\ Universidade Federal da Grande Dourados \\ gcmartinsreal@gmail.com
}

Eixo 01: Política, gestão e financiamento da educação a distância

\begin{abstract}
Resumo: Este estudo busca investigar em que medida a oferta de cursos de graduação realizados na modalidade a distância contribuiu para o crescimento da graduação ofertada pela UFGD, no período de 2013 a 2018. Realizou-se levantamento do que foi previsto para a implantação do Programa REUNI e para o PDI da UFGD, pois ambos previam a expansão da oferta de vagas na graduação. Com base em dados coletados do Censo da Educação Superior, verificou-se o quadro de matriculados no Brasil, na Região Centro-Oeste e na UFGD. A partir da análise, conclui-se que a contribuição dos cursos EaD é significativa nesse processo de expansão, considerando principalmente que atende a um público que geralmente não possui condições para frequentar a graduação presencial.
\end{abstract}

Palavras-chave: Educação a distância. Expansão. Graduação.

\section{Introdução}

A $\mathrm{EaD}$ tem sido considerada uma das mais importantes alternativas para suprir as lacunas do ensino presencial, sendo apontada como uma modalidade de ensino inovadora, em razão de suas áreas de atuação, da flexibilização tempo-espaço-lugares, principalmente para as pessoas que precisam estudar e trabalhar, ajustando-se aos horários e locais disponíveis de seu

1 Universidade Federal da Grande Dourados, Técnica de nível superior, Dourados, MS, Brasil. Contato: fsreginafarias@gmail.com

2 Universidade Federal da Grande Dourados, Faculdade de Educação, Programa de Pós-Graduação em Educação, Dourados, MS, Brasil. Contato: gcmartinsreal@gmail.com 


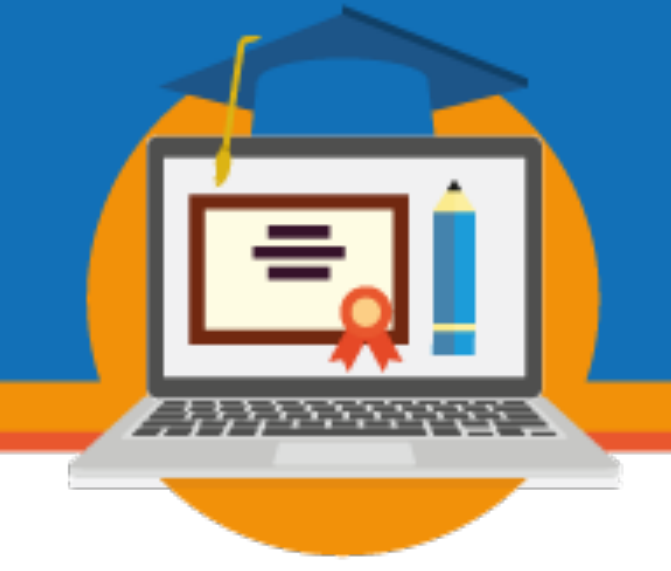

público. Talvez, por essa razão, crescem também as discussões sobre o fato de a EaD estar sendo desafiada a apresentar maior qualidade ou melhores resultados - ou, pelo menos, iguais aos da educação presencial.

No contexto geral, há inúmeros trabalhos publicados, que vão desde a implantação histórica da EaD no Brasil, a expansão ligada ao planejamento exigido para esta modalidade, a utilização de ferramentas de $\mathrm{EaD}$ em cursos presenciais, as dificuldades encontradas, as possibilidade didáticas que estas oferecem às suas práticas cotidianas. Os diversos papéis que o professor assume na $\mathrm{EaD}$ (professor, formador, mediador, tutor). As limitações enfrentadas pelos docentes na disponibilização de material, formulação de atividades e de testes avaliativos. Políticas públicas, legislações, design de plataformas, salas com muitos alunos... são temas que permeiam a discussão da EaD.

Haas, Celia María et al (2019) afirmam que a EaD vem se expandindo em um cenário sem controle, onde o desafio é verificar se é possível a oferta com qualidade, concomitante com o acesso.

O Brasil tem desafios consideráveis a serem enfrentados no que se refere à EaD, entre estes pode-se destacar a questão da qualidade da educação oferecida, incluindo nesta a prestação de serviço, o acesso e a permanência dos alunos na educação superior, a utilização das tecnologias digitais e a expansão da modalidade (HAAS et al, 2019, p.1).

A EaD veio para ficar, está presente na realidade educacional brasileira há mais de um século, e desde a sua implementação na UFGD, esta vem se ajustando para o atendimento da legislação posta.

\section{O estado do conhecimento da expansão na educação a distância brasileira}

Para conhecer quais as discussões que permeiam a educação a distância relacionada ao seu cenário de expansão, pesquisamos na plataforma Scientific Electronic Library Online (Scielo), a fim de localizar o estado do conhecimento do tema, buscando pelos termos (ead) and (educação a distância) and (expansão), quando obtivemos 15 trabalhos: 
Quadro 1. Estado do conhecimento de estudo dos termos da pesquisa (Scielo)

\begin{tabular}{|c|c|}
\hline Trabalhos, autores e publicação & Resumo \\
\hline 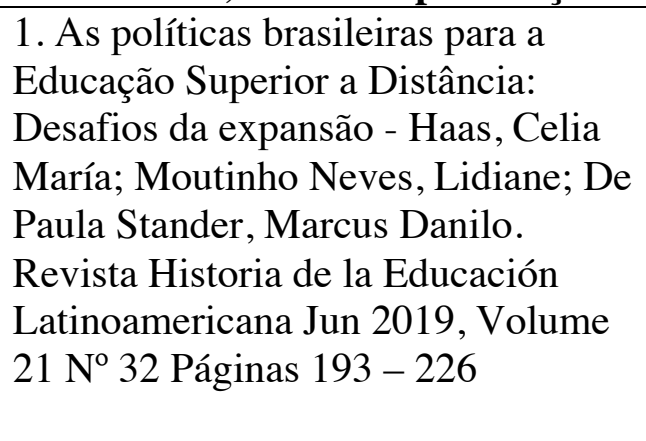 & $\begin{array}{l}\text { Analisa a trajetória das políticas para esta modalidade } \\
\text { e refletir acerca dos desafios que seu crescimento vem } \\
\text { colocando para assegurar a qualidade da educação, } \\
\text { complementada com cuidadosa revisão de literatura a } \\
\text { partir de autores que discutem o tema. [...] destaca a } \\
\text { questão da qualidade da educação oferecida, incluindo } \\
\text { nesta a prestação de serviço, o acesso e a permanência } \\
\text { dos alunos na educação superior, a utilização das } \\
\text { tecnologias digitais e a expansão da modalidade. }\end{array}$ \\
\hline $\begin{array}{l}\text { 2. Políticas Públicas em Educação } \\
\text { Superior a Distância - Um estudo } \\
\text { sobre a experiência do Consórcio } \\
\text { Cederj - Assumpção, Georgia de } \\
\text { Souza; Castro, Alexandre de } \\
\text { Carvalho; Chrispino, Álvaro. } \\
\text { Ensaio: Avaliação e Políticas } \\
\text { Públicas em } \\
\text { Educação Mar } 2018 \text {, Volume } 26 \text { N }^{\circ} \\
99 \text { Páginas } 445-470\end{array}$ & $\begin{array}{l}\text { Um panorama geral sobre as Políticas Públicas em } \\
\text { educação superior a distância, abordando as } \\
\text { legislações mais relevantes que tratam de sua } \\
\text { regulamentação, principais características, aspectos } \\
\text { gerais da modalidade. A partir dos estudos realizados } \\
\text { ficou esclarecido que a EAD se mostra como uma } \\
\text { ferramenta importante no processo de Políticas } \\
\text { Públicas para ampliação da educação superior no país. }\end{array}$ \\
\hline $\begin{array}{l}\text { 3. Expansão dos cursos públicos de } \\
\text { Serviço Social entre os anos de } 2003 \\
\text { e 2016: desafios para a formação } \\
\text { profissional } \\
\text { Pereira, Larissa Dahmer. } \\
\text { Revista } \\
\text { Katálysis Jan } 2018 \text {, Volume } 21 \text { N }^{\circ} 1 \\
\text { Páginas } 189 \text { - } 199\end{array}$ & $\begin{array}{l}\text { O artigo analisa dados referentes aos cursos públicos } \\
\text { de Serviço Social, criados entre } 2003 \text { e } 2016 \text {, } \\
\text { coletados no sistema eMEC. Como resultados, } \\
\text { constata-se que o período em análise (2003 a 2016) } \\
\text { criou mais da metade dos cursos públicos de Serviço } \\
\text { Social, com significativo impacto para a formação na } \\
\text { área pública. No mesmo período, o setor privado } \\
\text { também cresceu expressivamente, com forte } \\
\text { mercantilização do ensino superior brasileiro e o uso } \\
\text { significativo da modalidade de Ensino a Distância } \\
\text { (EaD) como estratégia de expansão lucrativa. }\end{array}$ \\
\hline $\begin{array}{l}\text { 4. Avaliação da educação superior } \\
\text { nas modalidades presencial e a } \\
\text { distância: análises com base no } \\
\text { Conceito Preliminar de Cursos } \\
\text { (CPC) - Oliveira, Édison Trombeta } \\
\text { de; Piconez, Stela Conceição } \\
\text { Bertholo. }\end{array}$ & $\begin{array}{l}\text { Com base em dados do Conceito Preliminar de Cursos } \\
\text { (CPC) para analisar as avaliações dos cursos de } \\
\text { graduação presenciais e a distância (EaD) no Brasil. } \\
\text { Esta análise não tem como propósito comparar as duas } \\
\text { modalidades de ensino nem delimitar qual é a ideal ou } \\
\text { o parâmetro a ser adotado. Breve discussão das } \\
\text { políticas de avaliação da educação superior brasileira }\end{array}$ \\
\hline
\end{tabular}


Avaliação: Revista da Avaliação da Educação Superior

(Campinas) Dez 2017, Volume $22 \mathrm{~N}$ o 3 Páginas $833-851$

5. Desempenho econômico da maior empresa de serviços educacionais do mundo: um estudo da Kroton

Educacional com base em seus segmentos operacionais -

Alves e Souza, Júlia; José

Mendonça, Douglas; Carmo da

Silva, Beatriz; Carvalho de

Benedicto, Gideon.

Cuadernos de

Contabilidad Dez 2017, Volume 18

No 46 Páginas $83-103$

6. A educação a distância em pesquisas acadêmicas: uma análise bibliométrica em teses do campo educacional

Mill, Daniel; Oliveira, Márcia

Rozenfeld G..

Educar em

Revista 2014, Nº spe4 Páginas 15 36

7. A EaD no Brasil: sobre (des)caminhos em sua instauração Alonso, Katia Morosov.

Educar em

Revista 2014, Nº spe4 Páginas 37 52

8. O valor das competências docentes no ensino da Administração

Kühl, Marcos Roberto; Maçaneiro, Marlete Beatriz; Cunha, João Carlos da; Cunha, Sieglinde Kindl da.

Revista de Administração (São e da expansão deste nível nos últimos anos, com ênfase na $\mathrm{EaD}$.

Uma análise do desempenho econômico da Kroton Educacional no período de 2011 a 2016, tendo por base as informações por segmentos operacionais referentes a essa empresa. [...] A partir do cálculo dos indicadores de lucratividade e de rentabilidade, observa-se que o segmento EAD foi o que mais contribuiu para a lucratividade da empresa. Já o segmento de ensino superior presencial, embora tenha sido responsável pela maior parte das receitas, não se destacou em termos de lucratividade ou de rentabilidade.

Analisa as relações entre os temas "Pesquisa" e "Educação a Distância" (EaD), buscando identificar as articulações entre a agenda de pesquisa sobre $\mathrm{EaD}$ e a evolução da área. [...]Os dados indicaram que a aproximação entre $\mathrm{EaD}$ e pesquisa ainda é tímida, mas foram encontrados indícios de que, também na $\mathrm{EaD}$, a agenda de pesquisas caminha articulada com a evolução da própria área de estudo.

Objetiva explicitar determinadas tendências e delineamentos presentes na oferta da educação a distância que indicam urgência na e para a avaliação desta política pública. [...] Diante disso, são levantados pontos a serem retomados/readequados na oferta da modalidade no sentido que, de fato, sejam cumpridos os objetivos propostos para seu desenvolvimento.

O objetivo neste estudo foi analisar a percepção de discentes da EaD quanto às competências docentes. Buscou-se responder à questão: Quais competências docentes são consideradas mais relevantes na opinião de discentes do Ensino a Distância? [...]Por fim, foram identificadas as competências percebidas pelos discentes de EaD como as mais relevantes na seguinte 


\begin{tabular}{|c|c|}
\hline $\begin{array}{l}\text { Paulo) Dez 2013, Volume } 48 \mathrm{~N}^{\circ} 4 \mathrm{P} \\
\text { áginas } 783-799\end{array}$ & $\begin{array}{l}\text { ordem: Postura, Didática, Relacionamento, } \\
\text { Conhecimento e Experiência. }\end{array}$ \\
\hline $\begin{array}{l}\text { 9. Formação de professores de } \\
\text { licenciatura a distância: o caso do } \\
\text { curso de pedagogia da } \\
\text { UAB/UECE } \\
\text { Nunes, João Batista Carvalho; Sales, } \\
\text { Viviani Maria Barbosa. } \\
\text { Educação e } \\
\text { Pesquisa Set } 2013 \text {, Volume } 39 \mathrm{~N}^{\mathrm{o}} 3 \\
\text { Páginas } 757-773\end{array}$ & $\begin{array}{l}\text { Trata da falta de qualificação de professores e a } \\
\text { dificuldade de acesso da população à educação } \\
\text { superior. [...] O trabalho tem como objetivo identificar } \\
\text { qual a formação dos professores atuantes no curso de } \\
\text { licenciatura em pedagogia da UAB/UECE [...]. Os } \\
\text { resultados evidenciam que ainda há um grande } \\
\text { número de docentes sem formação específica em EaD } \\
\text { para atuar no curso. }\end{array}$ \\
\hline $\begin{array}{l}\text { 10. Educação a distância: tensões } \\
\text { entre o público e o privado } \\
\text { Giolo, Jaime. } \\
\text { Educação \& } \\
\text { Sociedade Dez } 2010 \text {, Volume } 31 \mathrm{~N}^{\mathrm{o}} \\
\text { 113Páginas } 1271 \text { - } 1298\end{array}$ & $\begin{array}{l}\text { Aborda a educação a distância (EaD) brasileira no } \\
\text { contexto da expansão da educação superior, verificada } \\
\text { depois da LDB/1996. O foco da análise são as ações } \\
\text { avaliativas e regulatórias do Estado e o contraponto } \\
\text { político da iniciativa privada, donde derivam três } \\
\text { grandes tensionamentos, a saber: a prevalência do } \\
\text { privado sobre o público; o problema da qualidade no } \\
\text { binômio educação presencial versus educação a } \\
\text { distância; e, finalmente, as controvérsias a respeito do } \\
\text { modelo de EaD a ser assumido (ou não) pelo Brasil. }\end{array}$ \\
\hline $\begin{array}{l}\text { 11. A formação de professores a } \\
\text { distância como estratégia de } \\
\text { expansão do ensino superior } \\
\text { Barreto, Raquel Goulart. } \\
\text { Educação \& } \\
\text { Sociedade Dez } 2010 \text {, Volume } 31 \mathrm{~N}^{\mathrm{o}} \\
\text { 113Páginas } 1299 \text { - } 1318\end{array}$ & $\begin{array}{l}\text { Este artigo visa analisar estratégias de regulação para } \\
\text { a expansão da formação de professores, focalizando os } \\
\text { modos pelos quais as tecnologias da informação e da } \\
\text { comunicação (TIC) têm sido recontextualizadas nas } \\
\text { políticas educacionais. }\end{array}$ \\
\hline $\begin{array}{l}\text { 12. A expansão do ensino superior } \\
\text { no Brasil e a EaD: dinâmicas e } \\
\text { lugares } \\
\text { Alonso, Kátia Morosov. } \\
\text { Educação \& } \\
\text { Sociedade Dez } 2010 \text {, Volume } 31 \mathrm{~N}^{\circ} \\
\text { 113Páginas } 1319-1335\end{array}$ & $\begin{array}{l}\text { Análise de documentos que instituem a educação a } \\
\text { distância no Brasil, mais especificamente no Decreto } \\
\text { que a regulamenta e nos Referenciais de Qualidade } \\
\text { Para a Educação Superior a Distância. Dois aspectos } \\
\text { são enfatizados: o relacionado à lógica de expansão da } \\
\text { educação superior que incide também sobre a } \\
\text { modalidade a distância e, intrínseco a essa modalidade } \\
\text { de ensino, a lógica estabelecida em sua organização, } \\
\text { fundamentada independentemente das naturezas dos } \\
\text { estabelecimentos de ensino superior, nos elementos a } \\
\text { serem dispostos na concretização de seus sistemas. }\end{array}$ \\
\hline
\end{tabular}




\begin{tabular}{|c|c|}
\hline $\begin{array}{l}\text { 13. Mercantilização do ensino } \\
\text { superior, educação a distância e } \\
\text { Serviço Social } \\
\text { Pereira, Larissa Dahmer. } \\
\text { Revista } \\
\text { Katálysis Dez } 2009 \text {, Volume } 12 \mathrm{~N}^{\mathrm{o}} 2 \\
\text { Páginas } 268-277\end{array}$ & $\begin{array}{l}\text { Este trabalho objetiva analisar o significado do } \\
\text { processo de mercantilização do ensino superior, sua } \\
\text { expansão entre os anos } 1980 \text { e } 1990 \text { e, } \\
\text { particularmente, a modalidade de educação a } \\
\text { distância. [...] Em seguida, apresenta o surgimento dos } \\
\text { cursos de Serviço Social em EaD, problematizando } \\
\text { como esta nova modalidade de ensino pode impactar } \\
\text { o perfil profissional defendido pelas Diretrizes } \\
\text { Curriculares da Associação Brasileira de Ensino e } \\
\text { Pesquisa em Serviço Social (ABEPSS). }\end{array}$ \\
\hline $\begin{array}{l}\text { 14. ProUni e UAB como estratégias } \\
\text { de EAD na expansão do ensino } \\
\text { superior - } \\
\text { Segenreich, Stella Cecília Duarte. } \\
\text { Pro- } \\
\text { Posições Ago } 2009 \text {, Volume } 20 \mathrm{~N}^{\circ} 2 \\
\text { Páginas } 205-222\end{array}$ & $\begin{array}{l}\text { Uma análise dos programas ProUni e UAB como } \\
\text { estratégias de Educação a Distância promovidas pelo } \\
\text { governo Lula na expansão e democratização do } \\
\text { Ensino Superior. [...] Constatou-se, ainda, um avanço } \\
\text { significativo no reconhecimento de que a educação a } \\
\text { distância não se resume a uma estratégia de } \\
\text { mercantilização e privatização do ensino e que precisa } \\
\text { ser pesquisada intensamente em termos de sua } \\
\text { utilização como política de Estado e em termos das } \\
\text { novas questões de ordem institucional e pedagógica } \\
\text { que suscita. }\end{array}$ \\
\hline $\begin{array}{l}\text { 15. Políticas e gestão da educação } \\
\text { superior a distância: novos marcos } \\
\text { regulatórios? Dourado, Luiz } \\
\text { Fernandes. } \\
\text { Educação \& } \\
\text { Sociedade Out } 2008 \text {, Volume } 29 \mathrm{~N}^{\circ} \\
\text { 104Páginas } 891-917\end{array}$ & $\begin{array}{l}\text { O artigo enfoca os novos marcos regulatórios do } \\
\text { processo expansionista e analisa as políticas } \\
\text { direcionadas à formação de professores, com especial } \\
\text { realce para a educação a distância no setor público. } \\
\text { Nessa direção, apresenta e analisa alguns indicadores } \\
\text { educacionais e busca apreender, no campo das } \\
\text { políticas propostas pelo MEC, o papel da " Nova } \\
\text { CAPES" como espaço de regulação das políticas de } \\
\text { formação de professores, enfatizando a expansão } \\
\text { pública, na modalidade EaD, por meio dos desafios da } \\
\text { consolidação da Universidade Aberta do Brasil } \\
\text { (UAB). }\end{array}$ \\
\hline
\end{tabular}

Fonte: elaboração própria a partir dos dados coletados na Plataforma Scielo (2020).

Registra-se que nenhum dos trabalhos resultantes da busca trabalhou especificamente a contribuição da EaD para o crescimento da oferta de vagas em uma determinada Instituição, como é o objetivo deste estudo.

O Portal INEP divulgou notícia relevante no contexto da EaD sobre os dados da expansão registrados no Censo da Educação Superior 2018: 


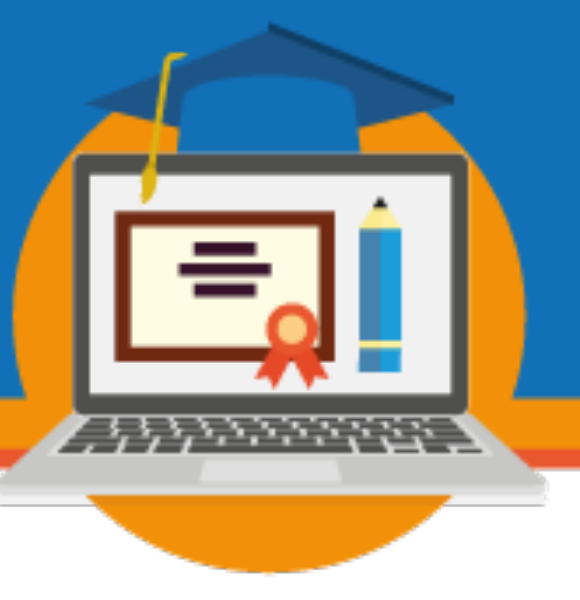

Pela primeira vez na série histórica, há mais vagas ofertadas na educação a distância (EaD), pelas instituições de educação superior, do que em cursos presenciais. O Censo da Educação Superior 2018 registrou 7,1 milhões de vagas na $\mathrm{EaD}$, enquanto os cursos presenciais contabilizam 6,3 milhões. $\mathrm{O}$ levantamento realizado, anualmente, pelo Instituto Nacional de Estudos e Pesquisas Educacionais Anísio Teixeira (Inep) revela ainda que, entre os 3,4 milhões de estudantes que ingressaram em cursos de graduação em 2018,40\% (1,4 milhão) optaram por cursos EaD. Já entre os que iniciaram cursos presenciais, houve queda no número total de ingressantes, entre 2017 e 2018. (Portal INEP, 2019).

Dada a relevância da investigação posta, passar-se-á aos objetivos, problemas e ao levantamento dos dados necessários à pesquisa, bem como o levantamento do contexto em que se deu a expansão dos cursos de graduação na UFGD.

\section{Objetivo e Questão da Pesquisa}

A Universidade Federal da Grande Dourados (UFGD) está localizada na cidade de Dourados, estado de Mato Grosso do Sul. Foi criada a partir do desmembramento da Universidade Federal de Mato Grosso do Sul no ano de 2005. Oferece cursos de graduação, pós-graduação lato e stricto sensu e Estágio Pós-Doutoral em alguns Programas de PósGraduação (UFGD, 2019-a).

Conforme consta na página oficial do Centro de Seleção da UFGD - Edital de abertura CCS n 08/2019 - PSV 2020, ofereceu 982 (novecentos e oitenta e duas) vagas para o PROCESSO SELETIVO VESTIBULAR UFGD 2020 para os cursos de graduação, nas modalidades presencial e a distância, distribuídas de acordo com a Lei n. ${ }^{\circ}$ 12.711/2012 e suas alterações. Destas 982, 30 foram ofertadas para o curso de Letras-Libras (UFGD, 2019-b). Oferece ainda vagas de ingresso por meio do Sistema de Seleção Unificada (SISU).

Este estudo pretende verificar a contribuição dos cursos ofertados na modalidade EaD para a expansão da oferta de vagas nos cursos de graduação da UFGD. Para tanto, buscará responder ao seguinte questionamento: Em que medida a EaD contribuiu para o aumento da oferta de vagas e matrículas nos cursos de graduação ofertados pela UFGD, no período de 2013 a $2018 ?$ 


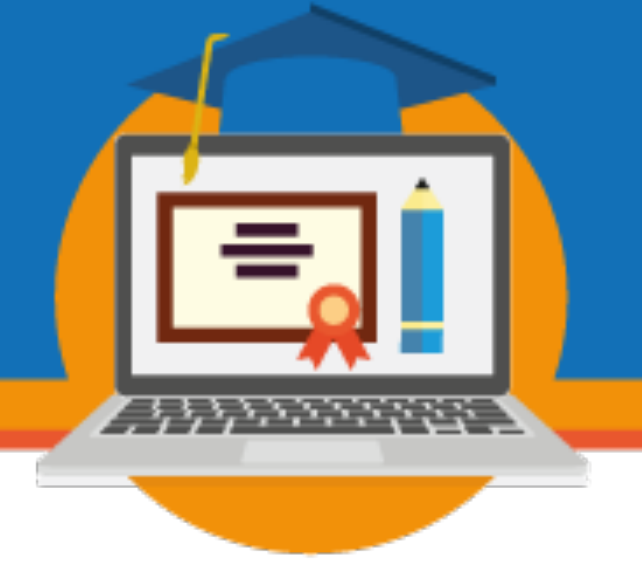

Nesse sentido, será verificada a previsão desta demanda no Plano de Desenvolvimento Institucional vigente para o período na UFGD, alinhada com a expansão prevista por meio do REUNI, no Brasil e no Mato Grosso do Sul, à luz dos dados oficiais fornecidos pelos órgãos competentes da UFGD.

\section{A EaD na UFGD}

A página da EaD UFGD apresenta a Faculdade de Educação a Distância - EaD da UFGD, que foi instituída oficialmente no dia 12 de agosto de 2014, quando passou ao patamar de faculdade, após aprovação do projeto pelo Conselho Universitário da UFGD (Res. COUNI/UFGD n 98 , de 12/08/2014), ofertando cursos de graduação e pós-graduação.

Atualmente, a faculdade oferta cursos em parceria com a Universidade Aberta do Brasil (UAB) e conta com dez polos de apoio presencial localizados em regiões estratégicas de Mato Grosso do Sul. Cada polo possui sua própria coordenação, com setor administrativo, professores, salas de aula e de estudo, laboratórios de informática, biblioteca e espaço de convivência. Os polos estão nas cidades de: Água Clara, Bataguassu, Bela Vista, Camapuã, Costa Rica, Japorã, Miranda, Porto Murtinho, Rio Brilhante e São Gabriel do Oeste. (UFGD, 2019-c).

\section{O contexto da expansão da graduação na UFGD: REUNI e PDI}

Lançado pelo governo federal brasileiro no ano de 2007, o Programa de Apoio a Planos de Reestruturação e Expansão das Universidades Federais (REUNI) foi estabelecido pelo Decreto $n^{\circ}$. 6.096, de 24 de abril de 2007, com o objetivo declarado de "criar condições para a ampliação do acesso e permanência na educação superior, no nível de graduação, pelo melhor aproveitamento da estrutura física e de recursos humanos existentes nas universidades federais" (BRASIL, 2007). 


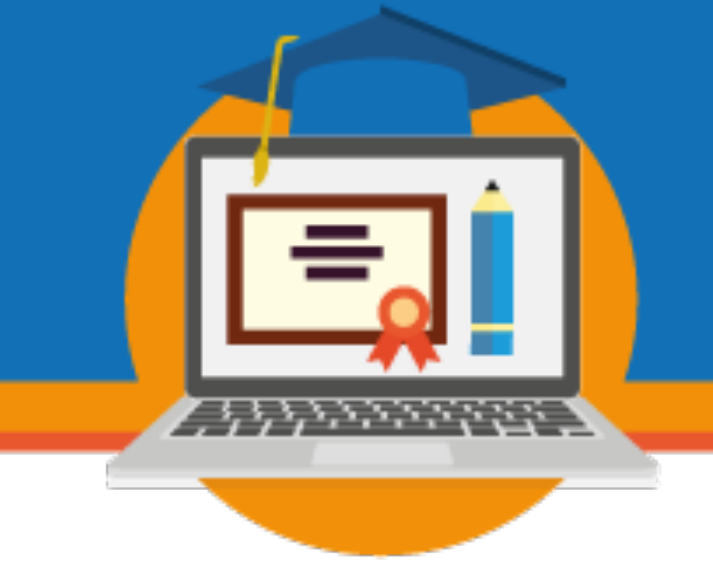

Na dissertação intitulada "Planos de Reestruturação e Expansão das Universidades Federais: O Reuni em Mato Grosso do Sul, Silva (2011) faz um apanhado descritivo da legislação que instituiu o REUNI:

\begin{abstract}
Segundo o documento intitulado "Diretrizes Gerais" (MEC, 2007), que complementa o Decreto que instituiu o REUNI, as universidades federais que aderiram ao programa receberão, de forma gradual, recursos para ampliação de estruturas física e tecnológica, além da contratação de docentes e técnicos. Como contrapartida aos investimentos, as universidades firmaram compromisso de obter, ao final dos cincos anos da implantação do REUNI, um percentual de $90 \%$ de conclusões nos cursos de graduação presencial além da relação de dezoito alunos por professor. Para adesão ao Programa REUNI, as universidades elaboraram seus Planos de Reestruturação e Expansão (Planos Institucionais) de acordo com as diretrizes estabelecidas pelo decreto, vinculando os repasses dos recursos financeiros às etapas estabelecidas nos Planos Institucionais com vistas ao alcance dos objetivos e metas do programa (SILVA, 2011, p. 17).
\end{abstract}

Silva (2011,p. 17-18) ainda situa o contexto do momento da expansão preconizada pelo REUNI na UFGD e no estado de Mato Grosso do Sul:

\begin{abstract}
O estado de Mato Grosso do Sul contava em 2009 com 45 instituições de educação superior (IES) e destas, cinco se organizam academicamente como universidade. Das universidades do estado, três são mantidas pelo poder público, e du'as são particulares. As duas universidades federais do estado, Universidade Federal de Mato Grosso do Sul (UFMS) e a Universidade Federal da Grande Dourados (UFGD) respondem por aproximadamente 25,3\% (INEP, 2010b) do total de matrículas em cursos de graduação presencial na educação superior do MS. [...] A UFGD e a UFMS aderiram ao Programa REUNI em outubro de 2007, quando houve a primeira chamada para adesão ao programa, com início das ações em 2008.
\end{abstract}

Dada sua implementação a partir de 2008, o Programa Reuni da UFGD previa a expansão da oferta de vagas na graduação. Era preciso então implementar a EaD na UFGD, para auxiliar no plano de crescimento desta oferta. Nesse contexto, foi aprovado o Plano de Desenvolvimento Institucional (PDI) por meio da Resolução COUNI/UFGD n 196, de 19/12/2013 para o período abrangido neste estudo, e este trazia em seu bojo a seguinte apresentação:

Criada em 2005 por desmembramento da UFMS, a Universidade Federal da Grande Dourados possuía 12 cursos de graduação [...]. Já em 2006, no início de sua instalação, foram criados mais 07 cursos de graduação e com o Programa REUNI, mais 09 cursos foram instalados, alcançando um total de 28 cursos de graduação na modalidade presencial, 02 cursos na modalidade a distância. [...] A UFGD ampliou de modo significativo as oportunidades de ensino em Mato Grosso do Sul, tanto na graduação quanto na pós-graduação. [...] Em 2005, o número de vagas totais dos cursos, considerando o número de vagas anuais ofertadas e o tempo de duração de cada curso era de 2.910, passando para $4.080 \mathrm{em}$

\title{
III SEMINÁRIO DE EDUCAÇÃO A DISTÂNCIA
}

Diálogos sobre EaD e uso das TDIC na educação: regulamentação em tempos recentes 3 a 6 de novembro de 2020 - Brasília/DF - Online 
presenciais e a distância, por meio de editais divulgados em seu sítio eletrônico, no link https://portal.ead.ufgd.edu.br/category/editais/.

\section{Análise dos dados obtidos}

\section{Matrículas nos Cursos de Graduação - Brasil, Centro-Oeste e UFGD - 2013 a 2018}

Tendo em vista o objetivo dessa pesquisa de analisar a contribuição dos cursos $\mathrm{EaD}$ da UFGD no processo de expansão dos cursos de graduação, traz-se aqui também para reflexão dados nacionais, da região Centro-Oeste e da UFGD, referentes aos alunos matriculados.

Quadro 2. Matrículas nos cursos de graduação presencial das IFEs, por ano e local

\begin{tabular}{|l|r|r|r|r|r|r|}
\hline Local & $\mathbf{2 0 1 3}$ & $\mathbf{2 0 1 4}$ & $\mathbf{2 0 1 5}$ & $\mathbf{2 0 1 6}$ & $\mathbf{2 0 1 7}$ & $\mathbf{2 0 1 8}$ \\
\hline Brasil & 1045507 & 108358 & 113317 & 117565 & 120495 & 1231909 \\
& & 6 & 2 & 0 & 6 & \\
\hline Centro-Oeste & 102901 & 108213 & 113167 & 117369 & 124768 & 127837 \\
\hline UFGD & 5745 & 6375 & 6518 & 6730 & 6869 & 6871 \\
\hline
\end{tabular}

Fonte: Sinopse censo da educação superior (INEP)

A partir da análise do quadro 2 identifica-se que no período de 2013 a 2018 no Brasil e na região Centro-Oeste ocorreu um aumento linear no número de matrículas, e de forma um pouco menos aparente, o mesmo processo ocorreu na UFGD.

Quadro 3 - Matrículas nos cursos de graduação a distância das IFES, por ano e local

\begin{tabular}{|l|r|r|r|r|r|r|}
\hline Local & 2013 & 2014 & 2015 & 2016 & 2017 & 2018 \\
\hline Brasil & 92344 & 96482 & 81463 & 73674 & 101395 & 93075 \\
\hline $\begin{array}{l}\text { Centro- } \\
\text { Oeste }\end{array}$ & 6249 & 7698 & 6254 & 5048 & 7523 & 5926 \\
\hline UFGD & 667 & 862 & 891 & 607 & 752 & 562 \\
\hline
\end{tabular}

Fonte: Sinopse censo da educação superior (INEP)

No quadro 3 é possível verificar que no Brasil o crescimento da EaD não é linear como nas graduações presenciais, sendo que em 2014 a quantidade de matrículas sobe, mas em 2015 
e 2016 decresce novamente, oscilando de forma mais intensa nos dois últimos anos. Com intensidades e períodos diferentes, as oscilações também ocorrem nas matrículas das IFEs do Centro-Oeste, tendo registro de aumento em 2014 e 2017. Na UFGD as matrículas nos cursos EaD cresceram em 2014 e 2015, mas caíram em 2017, quando diminui 286 matrículas, tendo encerrado 2018 com total de vagas menor que em 2013.

Quadro 4 - Percentual de matrículas nos cursos EaD x matriculados nas graduações das IFEs

\begin{tabular}{|l|c|c|c|c|c|c|}
\hline Local & $\mathbf{2 0 1 3}$ & $\mathbf{2 0 1 4}$ & $\mathbf{2 0 1 5}$ & $\mathbf{2 0 1 6}$ & $\mathbf{2 0 1 7}$ & $\mathbf{2 0 1 8}$ \\
\hline Brasil & $8 \%$ & $8 \%$ & $7 \%$ & $6 \%$ & $8 \%$ & $7 \%$ \\
\hline Centro-Oeste & $6 \%$ & $7 \%$ & $5 \%$ & $4 \%$ & $6 \%$ & $4 \%$ \\
\hline UFGD & $10 \%$ & $12 \%$ & $12 \%$ & $8 \%$ & $10 \%$ & $8 \%$ \\
\hline
\end{tabular}

Fonte: construção própria a partir dos dados da Sinopse Censo da Educação Superior (INEP)

Quando comparamos o percentual de matrículas dos cursos presenciais e a distância, podemos observar no quadro 4 que no Brasil o percentual dos cursos a distância contribuiu com $8 \%$ do total, chegando a $6 \%$ em 2016. Na região Centro-Oeste, o percentual foi menor no Brasil, chegando a 4\% em 2016 e 2018. Contudo, a UFGD se destaca tendo um percentual de matrículas nos cursos de graduação, que chegou a 12\% em 2014 e 2015 e em todo o período foi maior que no cenário nacional e no Centro-Oeste, fato que aponta que a contribuição dos cursos $\mathrm{EaD}$ foi significativo para o processo de expansão da UFGD.

\section{Considerações finais}

Por meio de decretos, portarias, portarias normativas, o MEC vem regulando a EaD conforme suas especificidades. Ainda, apresenta os Referenciais de Qualidade para a Educação Superior a Distância com o intuito de direcionar as IES sobre as diretrizes e critérios referentes à Educação Superior a Distância, que regula principalmente os quesitos a serem contemplados nos projetos político-pedagógicos dos cursos ofertados.

Desde sua criação, a UFGD vem se adequando a estas diretrizes e leis, no que tange às concepções didático-pedagógicas, infraestrutura física e de formação de recursos humanos interdisciplinares, gestão e de recursos financeiros. A partir da Portaria MEC n 1.134 , de 10 de 


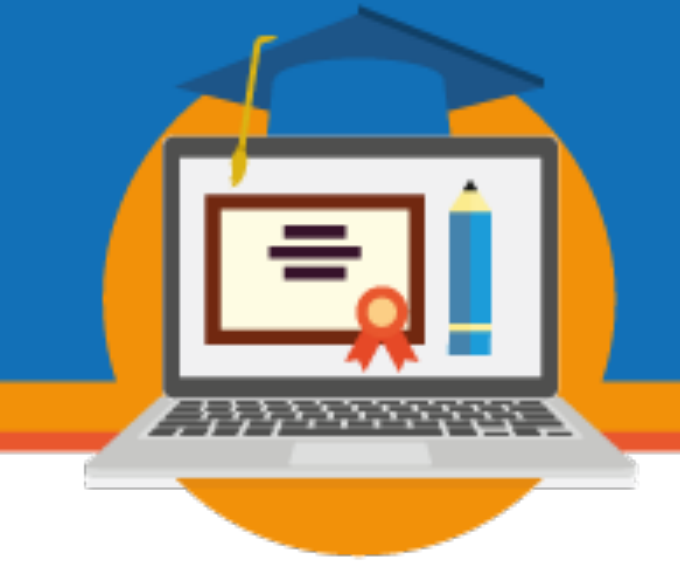

outubro de 2016 (ABMES, 2019), ajustou todos os seus projetos pedagógicos de graduação, buscando viabilizar a oferta da educação a distância prevista, de até $20 \%$ de seu conteúdo nos cursos presenciais. Recentemente, o MEC publicou a Portaria $n^{\circ} 1.428$, de 28 de dezembro de 2018 (Portal MEC, 2019), que revogou a anterior. A mudança só não engloba cursos de Engenharias e Saúde.

$\mathrm{O}$ crescimento da oferta de vagas analisadas neste estudo permite inferir que a $\mathrm{EaD}$ tem relevância no processo de incremento da oferta de vagas como um todo na UFGD. Muitos percalços permanecem na gestão e oferta da $\mathrm{EaD}$, principalmente porque o seu crescimento e mesmo o surgimento na maioria das IES públicas se deu no contexto da Universidade Aberta do Brasil - UAB, cujos recursos escassearam nos últimos anos. Mas é fato que a EaD se estabelece hoje como modalidade e opção necessária, no mundo, no Brasil e na UFGD, enquanto possibilidade de formação que dispensa a presença física no mesmo espaço, tempo e lugar dos formadores e seu público.

\section{Referências}

Associação Brasileira das Mantenedoras de Ensino Superior (ABMES). Portaria MEC n¹.134, de 10 de outubro de 2016. Disponível em: https://abmes.org.br/arquivos/legislacoes/Port-MEC1134-2016-10-10.pdf. Acesso em 19 nov 2019.

Ministério da Educação - MEC. "Referenciais de Qualidade para Educação Superior a Distância”. Brasília, DF: MEC, 2007. Disponível em: http://portal.mec.gov.br/seed/arquivos/pdf/legislacao/refead1.pdf. Acesso em: 20 jan 2020-a.

Ministério da Educação - MEC. Portaria MEC n 1.428, de 28 de dezembro de 2018. Disponível em

http://portal.mec.gov.br/index.php?option=com docman\&view=download\&alias=108231portaria-1428\&category_slug=fevereiro-2019-pdf\&Itemid=30192. Acesso em 18 nov 2019. 


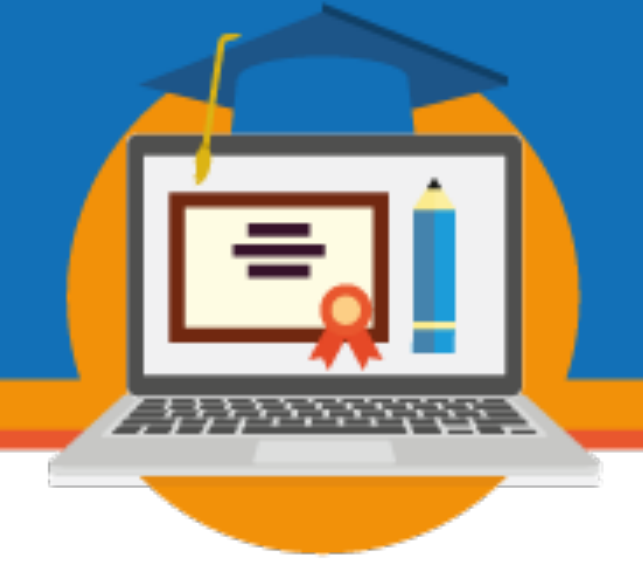

HAAS, Celia María; MOUTINHO NEVES, Lidiane; DE PAULA STANDER, Marcus Danilo. As políticas brasileiras para a Educação Superior a Distância: Desafios da expansão. Revista Historia de la Educación Latinoamericana Jun 2019, Volume 21 Nº 32 Páginas 193 226.

INEP. Portal de Notícias. Dia Nacional da Educação a Distância marca a expansão de ofertas de cursos e aumento do número de alunos matriculados. Disponível em: http://portal.inep.gov.br/artigo/-/asset_publisher/B4AQV9zFY7Bv/content/dia-nacional-daeducacao-a-distancia-marca-a-expansao-de-ofertas-de-cursos-e-aumento-do-numero-dealunos-matriculados/21206. Acesso em 10 jan 2020.

Plataforma Scielo. Disponível em: Pesquisa de termos. https://search.scielo.org/?q=\&lang=pt\&count $=15 \&$ from $=0$ \&output=site \&sort $=\&$ format $=$ sum mary $\& \mathrm{fb}=\&$ page $=1 \& \mathrm{q}=\% 28 \mathrm{ead} \% 29+\mathrm{AND}+\% 28 \mathrm{educa} \% \mathrm{C} 3 \% \mathrm{~A} 7 \% \mathrm{C} 3 \% \mathrm{~A} 3 \mathrm{o}+\mathrm{a}+\mathrm{dist} \% \mathrm{C} 3 \% \mathrm{~A}$ 2ncia\%29+AND+\%28expans\%C3\%A3o\%29\&lang=pt\&page=1. Acesso em 24 fev 2020.

SILVA, Ana Maria. Planos de Reestruturação e Expansão das Universidades Federais: O REUNI em Mato Grosso do Sul. Dissertação de Mestrado. Faculdade de Educação - Dourados, MS: UFGD, 2011. 144f.

Universidade Federal da Grande Dourados - UFGD. Histórico da Instituição. Disponível em: https://portal.ufgd.edu.br/reitoria/aufgd/historico. Acesso em 15 dez 2019-a.

Universidade Federal da Grande Dourados - UFGD. Centro de Seleção. Edital de abertura do Processo Seletivo UFGD 2020. Disponível em: https://cs.ufgd.edu.br/download/Edital de Abertura CCS 082019 PSV 2020 consolidado 22_11.pdf. Acesso em $18 \mathrm{dez}$ 2019-b.

Universidade Federal da Grande Dourados. Educação a Distância. Apresentação da EaD UFGD. Disponível em: https://portal.ead.ufgd.edu.br/a-ead/. Acesso em 10 out 2019-c. 